\title{
Innovación del gobierno colombiano para el sector minero energético*
}

\author{
Colombian Governmental Innovation for the Energy Mining Sector
}

Tomás González ${ }^{(1)}$
(1) Viceministro, Ministerio de Minas y Energía. Bogotá D.C., Colombia. tgonzalez@minminas.gov.co

Recibido 26 de julio de 2011, aprobado 26 de julio de 2011.

\begin{abstract}
Palabras Claves
Innovación, Colombia, minería, energía, gobierno colombiano.

\section{Resumen}

En Colombia es evidente la necesidad de innovar en el sector público. En este artículo se presenta el caso específico de la innovación del gobierno en el sector minero. Para esto, se iniciará con la identificación del potencial minero en Colombia y las barreras para su explotación. En seguida se explorarán los planes de innovación del gobierno como una estrategia para sobrepasar aquellas barreras que impiden aprovechar este potencial.
\end{abstract}

\section{Key words}

Innovation, Colombia, mining, energy, Colombian government.

\begin{abstract}
The need to innovate the public sector in Colombia is evident. This article presents the specific case of governmental innovation within the mining sector. It begins with the identification of mining potential in Colombia and the barriers that impede its exploitation. It is concluded by exploring governmental innovation plans that seek to overcome those barriers to take full advantage of Colombia's potential.
\end{abstract}

\section{INTRODUCCIÓN}

Ésta es la historia de innovación en el gobierno colombiano en el sector minero. El artículo se divide en: el potencial colombiano en minería, las barreras para explotarlo y la innovación en el gobierno entorno a este potencial.

\section{Potencial}

El potencial en minería se puede entender a través de tres cifras, las cuales indican hacia dónde se debe canalizar el esfuerzo del gobierno. La primera cifra tiene que ver con que Colombia tiene el $46 \%$ de las reservas del carbón de Latinoamérica y del Caribe, más o menos lo mismo que Brasil pero con carbón de mejor calidad. Así mismo, el país tiene un depósito de clase mundial en oro y un gran potencial en otros minerales como el cobre.

La segunda cifra tiene que ver con la inversión extranjera: el interés de los inversionistas por Colombia es inmenso y más del $80 \%$ de la inversión extranjera, en este momento, se dirige al sector de minas e hidrocarburos, y al sector minero energético.

La tercera cifra se refiere al enorme potencial de utilizar las reservas con las que cuenta el país y el interés de los inversionistas para generar crecimiento e inversión social. El PIB actual, en el caso minero, es de aproximadamente 5. 200 millones de dólares y se espera incrementarlo en los próximos 10 años, y llegar a 13 mil millones de dólares. Lo anterior se traduce en crecimiento y en recursos para inversión social: 100 billones de pesos en regalías, es decir, 20 puntos del PIB de hoy.

\section{BARRERAS}

Como el potencial actualmente no se está aprovechando, es necesario preguntarse cuáles son las barreras que permiten esta situación. La primera barrera es la contratación eficiente, en el momento en que un inversionista desea buscar un mineral en Colombia. Hasta el año 2010, los inversionistas se demoraban 570 días en obtener un título; esto hacía muy difícil materializar el potencial pues había una acumulación de solicitudes inmensa de procesar. A inicios del 2010, había 14.000 solicitudes represadas, respecto a las cuales se debía decidir si cumplían o no lo requisitos para tener un título minero.

* Éste artículo es la transcripción de la ponencia de Tomás González en la mesa redonda "Posibilidades y estrategias para la innovación a partir de las industrias de hidrocarburos, minería y energía en Colombia", que se llevó a cabo en el foro “Innovación en los sectores de la minería y la energía”, realizado en la Universidad de los Andes el día 26 de julio de 2011. 
La segunda barrera es la fiscalización. Por un lado, no se alcanzaban a hacer las visitas a todos los títulos entregados en el país y, por otro, la fiscalización no estaba teniendo los niveles de calidad necesarios para poder determinar si las actividades se desarrollaban de la manera esperada (seguridad industrial y temas ambientales, laborales y de producción). Por tanto, no se podía saber si las regalías que se estaban recibiendo empataban con la producción.

La tercera gran barrera es el conocimiento del subsuelo. En este momento, sólo se tiene una cartografía básica del $51 \%$ del territorio nacional, razón por la cual existe un enorme potencial desconocido que dificulta la orientación de la inversión y, por ejemplo, la realización de subastas de depósitos interesantes, como lo que hace la Agencia Nacional de Hidrocarburos - ANH.

Finalmente, otra barrera es la ausencia de promoción y fomento agresivos y focalizados. Por su parte, los hidrocarburos tienen mucho éxito gracias a la Agencia Nacional de Hidrocarburos, que recorre el mundo vendiendo a Colombia y trayendo inversiones que se adecúen a las necesidades y al potencial de hidrocarburos existente. Por el contrario, en el caso de la minería, la inversión en general es ad hoc y el fomento pasa principalmente por problemas de crédito y capacitación.

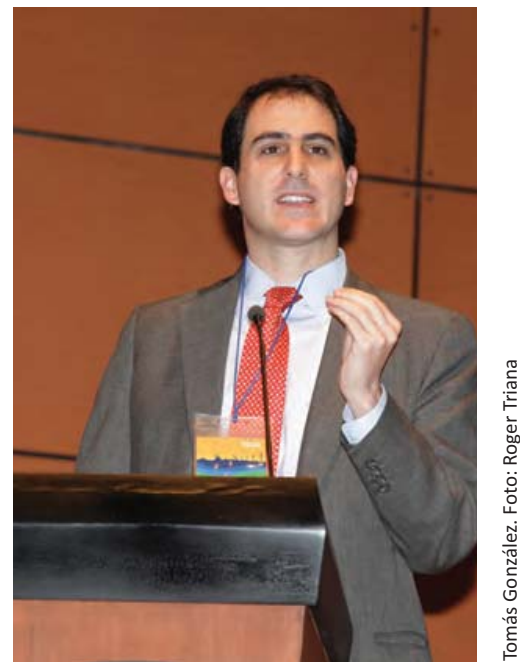

\section{INNOVACIÓN EN EL GOBIERNO NACIONAL}

Ante este panorama, es indudable que las cosas deben hacerse de manera diferente. Y de eso se trata precisamente la innovación, de marcar diferencias para generar un mayor valor. Ahora bien, el gran problema que se presenta es la dificultad de innovar desde el gobierno nacional.

El gran sesgo hacia el status quo en el gobierno tiene sus causas. La primera es que en el gobierno se premia la estabilidad sobre el cambio: la gente quiere que el gobierno sea confiable y que los servicios se presten de manera regular. La segunda es que es riesgoso cambiar: en Colombia ha habido tantos malos manejos y tantos abusos con los recursos públicos, que la solución ha sido el control; en efecto, el costo de los mecanismos de control es el miedo al cambio. La innovación, por su parte, tiene un componente de manejar fracasos y arriesgarse, dos cosas que no son el negocio del sector público. En consecuencia, es muy difícil que alguien se atreva a hacer cosas diferentes.

La tercera causa se refiere a que no hay un marco de liderazgo adecuado, orientado a la innovación. No hay una conciencia de los temas de liderazgo que se centren en empoderar a la gente que toma decisiones y en integrar los equipos de trabajo. Casi en todos los problemas del sector público interviene más de una entidad y si no hay una integración entre equipos es muy difícil tomar decisiones. Entonces, para hacer innovaciones, se debe empoderar a las personas que trabajan en estas entidades o tener un marco de liderazgo que facilite la integración.

Es claro que hay un potencial enorme, unas barreras grandes - de las cuales es responsable fundamentalmente el gobierno- y unas dificultades para innovar. La perspectiva es un poco desesperanzadora, sin embargo, es posible que este panorama cambie, pues en el caso de la minería se están haciendo diferencias dentro de las reglas del sistema; se está integrando a las personas y a las entidades que representan, con el propósito de hacer cambios para generar los resultados esperados al tiempo que se minimicen los riesgos.

Para remover estas barreras, en el caso de la contratación, se creó un plan de choque al armar equipos conformados por ingenieros, abogados y economistas, quienes procesan con celeridad y responsabilidad las solicitudes. Ante la presión, se estableció un esquema para tener 3 turnos de 8 horas los 7 días de la semana, para que en el 2011 se evacúen todas las solicitudes represadas.

Ahora bien, la esencia de un sistema de minería es el catastro, pues es él se registran los títulos y las actividades inscritas a ellos. Si no se tiene un buen catastro, no se pueden entregar bien las áreas ni se tiene un control de su evolución. En Colombia, por lo general se ha hecho una gran inversión en software; nos obstante, tras el análisis de los expertos y la inspiración de lo hecho en otras latitudes, se concluyó que, en el problema del Catastro, el software corresponde sólo al $5 \%$ y que el restante $95 \%$ del problema se relaciona con los procesos asociados a conseguir y alimentar la información. Para llegar a esta conclusión, se tuvo que generar un cambio importante, debido en gran parte al respaldo jurídico y legal para visibilizar las debilidades y detectar los problemas existentes; así se cambió a un software moderno, como el que funciona en muchos otros países del mundo y que solucionaba errores que arrojaba el anterior (por ejemplo, el anterior catastro permitía entregar títulos mineros en Venezuela).

Respecto a la fiscalización adecuada, hay que anotar que el mecanismo de fiscalización se divide en la parte documental y en las visitas al terreno; estas últimas, siempre se hacen con profesionales contratados por Ingeominas. Sin embargo, inspirados en las experiencias exitosas en otros campos (como el recaudo en Transmilenio S.A.), se hicieron unos términos de referencia para tercerizar la fiscalización. Por tanto, se hará un proceso abierto para contratar este servicio; se espera conseguir firmas con 
buena reputación, con experiencia en altos estándares en fiscalización, que puedan cumplir con las necesidades requeridas y que den garantías. Por otra parte, el gobierno, los vigilados y los fiscalizados deben pagar este servicio. Lo anterior revolucionará la minería, porque se conocerá a fondo lo que está pasando en Colombia, se tendrá una enorme base de datos de temas ambientales y laborales, de seguridad industrial y de producción, que permitirá focalizar mejor la política y acertar en la acción pública.

El conocimiento de subsuelo es un punto fundamental en esta industria. Tras la discusión en el Congreso de la República, se decidió que, dentro de la Reforma de Regalías, el 2\% de los recursos fuera para hacer fiscalización y conocimiento del subsuelo. Esto supone una fuente muy grande de recursos que harpa posible orientar mejor la minería. La reforma institucional, que está en curso y que muy próximamente se presentará al país, también se propone especializar la labor de conocimiento del subsuelo en una agencia. La Agencia Científica de Geología se encargará de darle el soporte de conocimiento del subsuelo al sector de hidrocarburos y minería.

El último punto es producción y fomento, que está en la reforma institucional. Se creará un departamento dedicado a la promoción minera especializado, el cual se dedicará atraer inversiones con altos estándares.

\section{ConClusión}

Los anteriores son ejemplos de innovación en curso a partir de las industrias de hidrocarburos, minería y energía en Colombia. Si se tiene éxito en el camino de integración, del intercambio con la gente y los esfuerzos de cambio, la minería va a cambiar completamente en el país. E Po último, es importante hacer énfasis en que una de las mayores fuentes de valor del país es la innovación en el sector público, pero se tiene que abrir un espacio en el sector público para que éste pueda innovar con tranquilidad y concentrarse en mejorar. 